\title{
Macular Carotenoid Supplementation in Subjects with Atypical Spatial Profiles of Macular Pigment
}

\author{
John Nolan \\ Waterford Institute of Technology \\ Mukunda Akkali \\ Whitfield Clinic, Waterford, Ireland \\ James Loughman \\ Technological University Dublin, james.loughman@tudublin.ie
}

See next page for additional authors

Follow this and additional works at: https://arrow.tudublin.ie/otpomart

Part of the Optometry Commons

\section{Recommended Citation}

Nolan, J., Akkali, M., \& Loughman, J. (2012). Macular carotenoid supplementation in subjects with atypical spatial profiles of macular pigment. Experiemental Eye Research, August;101:9-15. doi: 10.1016/ j.exer.2012.05.006.

This Article is brought to you for free and open access by ARROW@TU Dublin. It has been accepted for inclusion in Articles by an authorized administrator of ARROW@TU Dublin. For more information, please contact arrow.admin@tudublin.ie, aisling.coyne@tudublin.ie, gerard.connolly@tudublin.ie.

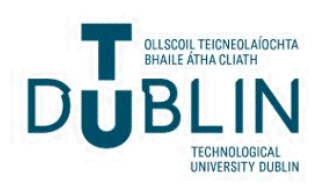




\section{Authors}

John Nolan, Mukunda Akkali, James Loughman, Alan Howard, and Stephen Beatty

This article is available at ARROW@TU Dublin: https://arrow.tudublin.ie/otpomart/36 


\section{Highlights}

- The meso-zeaxanthin supplement normalises the spatial profile of macular pigment. Meso-zeaxanthin is required to realise central MP in atypical profiles. $>$ All three macular carotenoids are needed for rapid augmentation of macular pigment.

0014-4835/\$ - see front matter (c) 2012 Published by Elsevier Ltd. doi:10.1016/j.exer.2012.05.006 


\title{
Macular carotenoid supplementation in subjects with atypical spatial profiles of macular pigment
}

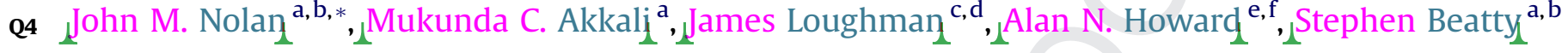 \\ ${ }^{a}$ Macular Pigment Research Group, Department of Chemical and Life Sciences, Waterford Institute of Technology, Waterford, Ireland \\ ${ }^{\mathrm{b}}$ Institute of Vision Research, Whitfield Clinic, Waterford, Ireland \\ ${ }^{\mathrm{c}}$ Macular Pigment Research Group, Optometry Department, Dublin Institute of Technology, Dublin, Ireland \\ ${ }^{\mathrm{d}}$ African Vision Research Institute, University of KwaZulu Natal, Faculty of Health Sciences, Durban, South Africa \\ e Downing College, University of Cambridge, Cambridge, UK \\ ${ }^{\mathrm{f}}$ The Howard Foundation, Cambridge, UK
}

\section{A R T I C L E I N F O}

Article history:

Received 10 March 2012

Accepted in revised form 18 May 2012

Available online $\mathrm{xxx}$

\section{Keywords:}

macular pigment

meso-zeaxanthin

zeaxanthin

lutein

age-related macular degeneration

\begin{abstract}
A B S T R A C T
This study was designed to investigate the impact of macular carotenoid supplementation on the spatial profile of macular pigment (MP) in subjects where the profile does not exhibit the typical central peak (i.e. peaked MP at foveal epicentre). Thirty one healthy subjects with such atypical MP spatial profiles were assigned to one of three intervention groups: Group 1: $(n=11), 20 \mathrm{mg} /$ day lutein (L), $2 \mathrm{mg} / \mathrm{day}$ zeaxanthin (Z); Group 2: $(n=10), 10 \mathrm{mg} /$ day meso-zeaxanthin (MZ), $10 \mathrm{mg} /$ day L, $2 \mathrm{mg} /$ day $Z$; Group 3: $(n=10), 17 \mathrm{mg} /$ day MZ, $3 \mathrm{mg} /$ day L, $2 \mathrm{mg} /$ day Z. Subjects were instructed to take one capsule daily over an 8 -week period. MP at $0.25^{\circ}, 0.5^{\circ}, 1^{\circ}, 1.75^{\circ}$ and $3^{\circ}$ was measured using customized-heterochromatic flicker photometry at baseline, four weeks and 8 weeks. Over the study period, we report no statistically significant increase in MP at any eccentricity in Group 1 ( $p>0.05$, for all eccentricities). There was a trend towards an increase in MP at all eccentricities in Group 2, with a significant increase found at $0.25^{\circ}$ and $0.50^{\circ}(p=0.000$ and $p=0.016$, respectively). There was a statistically significant increase evident in MP at $0.25^{\circ}$ in Group $3(p=0.005)$, but at no other eccentricity $(p>0.05$, for all other). We report that the typical central peak of MP can be realised in subjects with atypical spatial profiles, following supplementation with a preparation containing all three macular carotenoids, but not with a supplement lacking MZ. The implications of our findings, in terms of visual performance and/or a (photo)-protective effect, warrant additional study.
\end{abstract}

(c) 2012 Published by Elsevier Ltd.

\section{Introduction}

The central retina, known as the macula, is responsible for colour and fine-detail vision (Hirsch and Curcio, 1989). A pigment, composed of the carotenoids, lutein (L), zeaxanthin (Z), and mesozeaxanthin (MZ), (Bone et al., 1997; Johnson et al., 2005) accumulate at the macula where they are collectively known as macular pigment (MP). MP is a blue light filter (Snodderly et al., 1984b) and a powerful antioxidant, (Khachik et al., 1997) and is therefore believed to protect against age-related macular degeneration (AMD), which is now the most common cause of blind registration in the western world (Klaver et al., 1998). In addition, MP's putative ability to enhance visual performance and comfort is also of

\footnotetext{
* Corresponding author. Macular Pigment Research Group, Department of Chemical and Life Sciences, Waterford Institute of Technology, Waterford, Ireland. Tel.: +35351834074.

E-mail address: jmnolan@wit.ie (J.M. Nolan).
}

interest (Bartlett and Eperjesi, 2008; Engles et al., 2007; Hammond and Wooten, 2005; Kvansakul et al., 2006; Loughman et al., 2010; Nolan et al., 2011; Rodriguez-Carmona et al., 2006; Stringham and Hammond, 2007, 2008; Stringham et al., 2004; Wooten and Hammond, 2002).

$\mathrm{Z}$ and $\mathrm{MZ}$ are the predominant carotenoid in the foveal region, whereas L predominates in the parafoveal region (Bone et al., 1988; Snodderly et al., 1991). The concentration of MZ peaks centrally, with the MZ:Z ratio of 0.82 (approximately) in the central retina (with in $3 \mathrm{~mm}$ of the fovea) and 0.25 in the peripheral retina $(11-21 \mathrm{~mm}$ from the fovea)(Bone et al., 1997). The above observations are most probably attributable to the fact that retinal MZ is produced primarily by isomerization of retinal L, (Johnson et al., 2005) thus accounting for lower relative levels of L, and higher relative levels of $\mathrm{MZ}$, in the central macula, and vice versa in the peripheral macula, and would also explain why MZ accounts for about one third of total MP, (Bone et al., 1993) in spite of its absence or low concentrations in a typical diet. 
MP represents the most conspicuous accumulation of carotenoids in the human body; however, its concentration has been shown to vary dramatically among individuals (Hammond et al., 1997). Typical MP profiles generally peak at the centre of the macula and decreases in concentration with increasing eccentricity out to the parafovea (Bone et al., 1988; Snodderly et al., 1984a). However, as mentioned above, variations in the distribution of MP have been reported ${ }_{1}$ (Berendschot and van Norren, 2006; Delori et al., 2006; Kirby et al., 2009). Recently, for example, it has been shown that atypical MP spatial profiles (i.e. those not exhibiting a typical central peak) are present in some individual MP profiles. More importantly, it has been confirmed that these atypical profiles are real and reproducible features of the MP spatial profile, when measured using customized ${ }_{3}$ heterochromatic flicker photometry (cHFP, a validated technique for measuring MP)(Kirby et al., 2009). The importance of such variations, if any, in the spatial profile of MP (e.g. the absence of a typical central peak) is not yet known, but may be related to the putative protective role of this pigment. For example, reduced MPOD at the centre of the macula may be associated with increased risk of developing AMD (given the lower antioxidant activity and short-wavelength light filtering capacity of such an individual, when compared to an individual with a typical central peak)(Trieschmann et al., 2003). Also, a recent study by our research group has shown that $12 \%$ (58 subjects out of a sample database of 484 subjects) of the healthy Irish population exhibit a reproducible atypical MP spatial profile (characterized by the lack of a typical central peak) and that such atypical MP spatial profiles are more common in older subjects and in cigarette smokers (two of the established risk factors for AMD) ${ }_{\Delta}$ (Kirby et al., 2010).

In brief, the current study has taken advantage of a unique opportunity, by inviting subjects from the above mentioned database $(n=58)$, (Kirby et al., 2010) who were identified, and confirmed, as exhibiting such an atypical MP spatial profile ${ }_{\Lambda}$ (see Fig. 1).

\section{Methods}

\subsection{Subjects and study design}

Fifty eight subjects with atypical MP spatial profiles (identified from our master MP database; $n=484$ ) were invited to revisit our

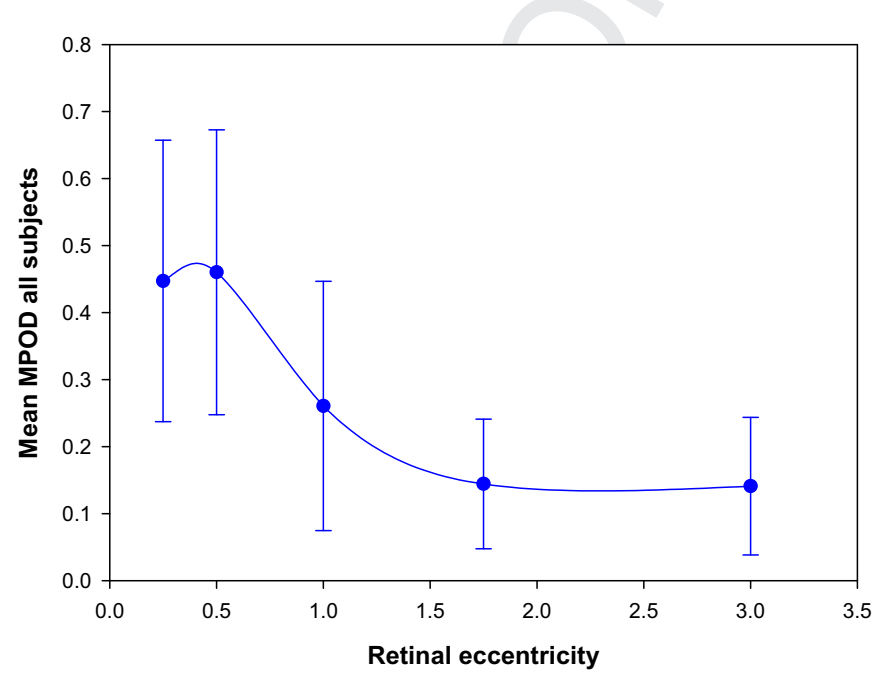

Fig. 1. Mean $( \pm S D)$ macular pigment optical density spatial profile for the entire study group $(n=30)$ at baseline. The smooth line drawn through the data was achieved using our graphic software Sigma Plot 8. vision science laboratories at the Waterford Institute of Technology (WIT) and Dublin Institute of Technology (DIT), Ireland, to confirm the presence of their atypical MP spatial profile. Of the forty subjects who agreed to come back for testing, thirty subjects were confirmed as still exhibiting an atypical MP profile as defined by our criteria (i.e. MPOD at $0.25^{\circ}$ did not exceed MPOD at $0.5^{\circ}$ of eccentricity by more than 0.04 optical density units) generated for the purpose of this study, and were therefore enrolled into the 8week supplementation trial with one of three different macular carotenoid formulations (see below).

Of the nine subjects who no longer exhibited an MP spatial profile sufficiently atypical for inclusion in the current study, because of our strict and predefined criteria, seven did exhibit a persistently atypical profile. With respect to the other two subjects, possible explanations as to why they no longer exhibited the previously observed atypical MP profile may rest on the interval between original testing and recall for the purpose of this study and/or changes in dietary habits (including possible supplementation).

All subjects signed an informed consent document and the experimental measures conformed to the Declaration of Helsinki. The study was reviewed and approved by the Research Ethics Committees of Waterford Institute of Technology, Waterford, Ireland, and Dublin Institute of Technology, Dublin, Ireland. Inclusion criteria for participation in this study were as follows: MPOD at $0.25^{\circ}$ did not exceed MPOD at $0.5^{\circ}$ of eccentricity by more than 0.04 optical density units (thereby defining "atypical" MP spatial profile for the purpose of this study); no presence of ocular pathology; corrected distance visual acuity (CDVA) 20/60 or better in the study eye; no current or prior use of supplements containing $\mathrm{L}$ and/or $\mathrm{Z}$ and/or MZ.

This was a randomized and double blind clinical trial with three interventions. Subjects were randomly assigned into one of the three groups as follows: Group 1: high L group $(n=10 ; \mathrm{L}=20 \mathrm{mg} /$ day, $Z=2 \mathrm{mg} /$ day); Group 2: combined carotenoid group ( $n=10$; $\mathrm{MZ}=10 \mathrm{mg} /$ day, $\mathrm{L}=10 \mathrm{mg} /$ day, $\mathrm{Z}=2 \mathrm{mg} /$ day); Group 3: high $\mathrm{MZ}$ group ( $n=10 ; M Z=17 \mathrm{mg} /$ day, $\mathrm{L}=3 \mathrm{mg} /$ day, $Z=2 \mathrm{mg} /$ day).

All subjects were instructed to take one capsule per day with a meal for 8 weeks. Significant efforts were made to ensure compliance to the study intervention. Weekly text messages and phone calls were made by the research team. In addition, subjects were requested to return their supplement packs at their exit visit, and compliance was checked by tablet counting at this visit.

MPOD, including its spatial profile, i.e. at $0.25^{\circ}, 0.5^{\circ}, 1^{\circ}, 1.75^{\circ}, 3^{\circ}$, was measured at baseline, four weeks and 8 weeks. The right eye was chosen as the study eye for all subjects, with the exception of one subject whose right CDVA did not meet the criteria for MP testing, and the left eye for that subject was, therefore, chosen as the study eye.

Demographic, lifestyle and vision information was also collected from each subject as follows: name; contact information; age; sex; smoking habits; medication and vision case history. CDVA was measured by logMAR chart. A subject's weekly intake of carotenoid rich foods (eggs, broccoli, corn, dark leafy vegetables) were inputted into the "L/Z screener" to give a carotenoid diet 'score'. Values were weighted for frequency of intake of the food and for the bioavailability of $\mathrm{L}$ and $\mathrm{Z}$ with in these foods and a ranking score reflecting the relative intakes was generated. Evaluation of the $\mathrm{L} / \mathrm{Z}$ screener against the Willet food frequency questionnaire yielded a positive correlation that was strongly significant $(p<0.01)$. The range of scores from the $L / Z$ screener is $0-75$. After adding foods with known concentrations of $\mathrm{L}$ and $\mathrm{Z}$ into the screener, the following estimates were made. Low dietary carotenoid intake score is from 0 to 15 (i.e. $\leq 2 \mathrm{mg} / \mathrm{d}$ ); medium dietary carotenoid intake score is from 16 to 30 (i.e. between $>2$ 
and $13 \mathrm{mg} /$ day); high dietary carotenoid intake score is from 31 to 75 (i.e. $>13 \mathrm{mg} /$ day).

\subsection{Measurement of macular pigment optical density}

The spatial profile of MP was measured using the Macular Densitometer ${ }^{\mathrm{TM}}$, a HFP instrument that is slightly modified from a device described by Wooten and Hammond (2005). A detailed discussion of the principle of HFP and its customization to accurately measure MP has also been described by Kirby et al. (2009). All subjects in this study previously had their MP spatial profile measured with the Macular Densitometer ${ }^{\mathrm{TM}}$ using the cHFP technique. In addition, further training was provided prior to testing. Therefore, all subjects in the current study were experienced with respect to the device and testing procedure. In order to measure the spatial profile of MP, we performed measurements at the following degrees of retinal eccentricity: $0.25^{\circ}, 0.5^{\circ}, 1^{\circ}, 1.75^{\circ}, 3^{\circ}$ and $7^{\circ}$ (the reference point) obtained using the following sized target diameters; 30 min, $1^{\circ}, 2^{\circ}, 3.5^{\circ}, 1^{\circ}$ and $2^{\circ}$, respectively. Stimulus 5 , our $3^{\circ}$ target, was $1^{\circ}$ diameter disc with its centre located $3^{\circ}$ from a black fixation point (i.e. the average of the inner arc which defines the disc at $2.5^{\circ}$ and the outer arc which defines the disc at $3.5^{\circ}$ ). Stimulus 6 , our reference point, is a $2^{\circ}$ diameter disc with its centre located $7^{\circ}$ from a red fixation point (i.e. the average of the inner arc which defines the disc at $6^{\circ}$ and the outer arc which defines the disc at $8^{\circ}$ ) as MPOD at this location is optically undetectable and its distribution at this location is essentially flat. Measurement of the spatial profile of MP using cHFP has previously been shown to be highly reproducible (ICC $=0.93,0.96$ ), and therefore does not account for change identified in the spatial profile of MP over time (either following, or without, dietary modification/ supplementation) when measured using this technique (Kirby et al., 2009, 2010).

\subsection{Statistical analysis}

The statistical software package PASW Statistics 17.0 (SPSS Inc., Chicago, Illinois, USA) was used for analysis and Sigma Plot 8.0 (Systat Software Inc., Chicago, Illinois, USA) was used for graphical presentations. All quantitative variables investigated exhibited a normal distribution. Means \pm SDs are presented in the text and tables. Statistical comparisons of the three different intervention groups, at baseline, were conducted using one way ANOVA and chisquare analysis, as appropriate.

We conducted repeated measures ANOVA for MPOD, including its spatial profile, for each intervention group, including each study visit, using a general linear model approach, with age as a covariate (as age was significantly different between the groups at baseline, see below). Bonferroni correction was applied as appropriate. We used the $5 \%$ level of significance throughout our analysis.

\section{Results}

\subsection{Baseline findings}

The demographic, lifestyle, CDVA, and MPOD data of all thirty one subjects recruited into the study, and divided by study arm (i.e. Group 1, Group 2, Group 3), are summarized in Table 1. As seen from this table, most variables under investigation did not differ significantly between these groups at baseline $(p>0.05$, for said variables). However, a significant baseline difference between these groups with respect to age $(p<0.01)$ was identified, with Group 3 having a significantly lower mean age when compared to Groups 1 and 2, and age was therefore controlled for throughout the remainder of the analysis.
Table 1

Demographic, lifestyle, visual acuity and macular pigment data at baseline.

\begin{tabular}{lllll}
\hline Characteristic & $\begin{array}{l}\text { All } \\
(n=30)^{\mathrm{a}}\end{array}$ & $\begin{array}{l}\text { Group1 } \\
(n=10)\end{array}$ & $\begin{array}{l}\text { Group 2 } \\
(n=10)\end{array}$ & $\begin{array}{l}\text { Group 3 } \\
(n=10)\end{array}$ \\
\hline Age & $47 \pm 14$ & $51 \pm 11^{\mathrm{b}}$ & $56 \pm 11^{\mathrm{b}}$ & $35 \pm 10^{\mathrm{b}}$ \\
Sex & & & & \\
$\quad$ Male & 9 & 3 & 3 & 3 \\
$\quad$ Female & 21 & 7 & 7 & 7 \\
Smoking habits & & & & \\
$\quad$ Never smoker & 19 & 7 & 7 & 5 \\
$\quad$ Ex-smoker & 10 & 2 & 3 & 5 \\
$\quad$ Current smoker & 1 & 1 & 0 & 0 \\
Positive FH of AMD & 8 & 3 & 2 & 3 \\
Diet score & $27 \pm 14$ & $34 \pm 15$ & $25 \pm 14$ & $22 \pm 13$ \\
Aided Visual acuity & $105 \pm 8$ & $105 \pm 8$ & $106 \pm 6$ & $107 \pm 4$ \\
MPOD & & & & \\
$\quad 0.25^{\circ}$ & $0.45 \pm 0.21$ & $0.46 \pm 0.21$ & $0.41 \pm 0.27$ & $0.48 \pm 0.16$ \\
$0^{\circ}$ & $0.46 \pm 0.21$ & $0.46 \pm 0.23$ & $0.44 \pm 0.26$ & $0.48 \pm 0.15$ \\
$1^{\circ}$ & $0.26 \pm 0.19$ & $0.20 \pm 0.19$ & $0.26 \pm 0.23$ & $0.32 \pm 0.12$ \\
$1^{\circ} .75^{\circ}$ & $0.14 \pm 0.10$ & $0.15 \pm 0.10$ & $0.18 \pm 0.10$ & $0.11 \pm 0.09$ \\
$3^{\circ}$ & $0.14 \pm 0.10$ & $0.14 \pm 0.11$ & $0.16 \pm 0.12$ & $0.12 \pm 0.08$ \\
\hline
\end{tabular}

a $n=$ sample size.

b $p<0.01$.

c Smoking habits: ex-smoker $=$ smoked $\geq 100$ cigarettes in lifetime but none in last 12 months; current smoker $=$ smoked $>100$ cigarettes in lifetime and at least 1 cigarette per week in last 12 months.

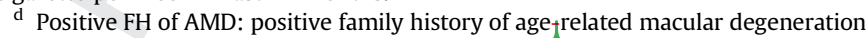
(self reported). Values represent mean \pm standard deviation; MPOD $=$ macular pigment optical density; $0.25^{\circ}=$ MPOD measured at $0.25^{\circ}$ retinal eccentricity; $0.5^{\circ}=$ MPOD measured at $0.5^{\circ}$ retinal eccentricity; $1^{\circ}=$ MPOD measured at $1^{\circ}$ retinal eccentricity; $1.75^{\circ}=$ MPOD measured at $1.75^{\circ}$ retinal eccentricity; $3^{\circ}=$ MPOD measured at $3^{\circ}$ retinal eccentricity; Group 1: high $\mathrm{L}$ group $(\mathrm{L}=20 \mathrm{mg} / \mathrm{day}$, $\mathrm{Z}=2 \mathrm{mg} / \mathrm{day}) ;$ Group 2: combined carotenoid group $(\mathrm{MZ}=10 \mathrm{mg} / \mathrm{day}$, $\mathrm{L}=10 \mathrm{mg} /$ day, $\mathrm{Z}=2 \mathrm{mg} /$ day); Group 3 : high $\mathrm{MZ}$ group $(\mathrm{MZ}=17 \mathrm{mg} /$ day, $\mathrm{L}=3 \mathrm{mg} /$ day, $\mathrm{Z}=2 \mathrm{mg} /$ day).

e A subject's weekly intake of carotenoid rich foods (eggs, broccoli, corn, dark leafy vegetables) were inputted into an $\mathrm{L} / \mathrm{Z}$ screener to give a carotenoid diet 'score'. Values were weighted for frequency of intake of the food and for the bioavailability of $\mathrm{L}$ and $\mathrm{Z}$ within these foods and an arbitrary score were generated and used to adjust for diet, as appropriate.

\subsection{Change in MPOD over 8-week supplementation period}

As seen in Table 2, increases in MPOD at $0.25^{\circ}$ and $0.5^{\circ}$ were statistically significant in Group 2. Similarly, a significant increase in MPOD at $0.25^{\circ}$ was seen in Group 3. Of note, after Bonferroni correction for multiple testing, the MPOD increase seen at $0.25^{\circ}$ in Group 2 was the only observed increase to remain statistically significant.

Changes in MPOD values over time, for each subject and for all eccentricities measured, are presented in Table 3. Change in the spatial profile of MPOD for each group is illustrated in Figs. 2-4. These figures graphically represent mean MPOD spatial profile for each group at baseline (pre supplementation) and at 8 weeks (post supplementation).

At 0.25 of eccentricity, a MPOD increase of $>10 \%$ was seen in 4 (40\%), 10 (100\%) and 8 (80\%) subjects in Groups 1, 2, and 3, respectively. Further, at this eccentricity, the average increase in MPOD (measured in optical density units) was 0.031 (13\%), 0.182 (102\%), and $0.094(22 \%)$ in Groups 1, 2 and 3, respectively. At 0.5 of eccentricity, a MPOD increase of $>10 \%$ was seen in 3 (30\%), 7 (70\%) and 5 (50\%) subjects in Groups 1, 2 and 3, respectively. Further, at this eccentricity, the average increases in MPOD (measured in optical density units) was 0.02 (13\%), 0.079 (27\%), and 0.019 (6\%), for these Groups, respectively.

\section{Discussion}

This is the first study designed to investigate the effect of macular carotenoid supplementation, with three different 
Table 2

Average MPOD values at each degree of retinal eccentricity for all subjects according

\begin{tabular}{llllll}
\hline Group & MPOD & Baseline & 4 wks & 8 wks & $\begin{array}{l}\text { Time interaction } \\
(p \text {-value })\end{array}$ \\
\hline Group 1 & $0.25^{\circ}$ & $0.46 \pm 0.21$ & $0.48 \pm 0.21$ & $0.49 \pm 0.22$ & 0.220 \\
Group 1 & $0.5^{\circ}$ & $0.46 \pm 0.23$ & $0.46 \pm 0.19$ & $0.48 \pm 0.23$ & 0.626 \\
Group 1 & $1^{\circ}$ & $0.20 \pm 0.19$ & $0.27 \pm 0.16$ & $0.25 \pm 0.14$ & 0.283 \\
Group 1 & $1.75^{\circ}$ & $0.15 \pm 0.10$ & $0.16 \pm 0.10$ & $0.15 \pm 0.09$ & 0.904 \\
Group 1 & $3^{\circ}$ & $0.14 \pm 0.11$ & $0.16 \pm 0.09$ & $0.11 \pm 0.08$ & 0.370 \\
& & & & & \\
Group 2 & $0.25^{\circ}$ & $0.41 \pm 0.27$ & $0.50 \pm 0.27$ & $0.59 \pm 0.30$ & 0.000 \\
Group 2 & $0.5^{\circ}$ & $0.44 \pm 0.26$ & $0.46 \pm 0.28$ & $0.52 \pm 0.28$ & 0.016 \\
Group 2 & $1^{\circ}$ & $0.26 \pm 0.23$ & $0.29 \pm 0.15$ & $0.34 \pm 0.10$ & 0.417 \\
Group 2 & $1.75^{\circ}$ & $0.18 \pm 0.10$ & $0.19 \pm 0.06$ & $0.22 \pm 0.06$ & 0.218 \\
Group 2 & $3^{\circ}$ & $0.16 \pm 0.12$ & $0.14 \pm 0.06$ & $0.19 \pm 0.11$ & 0.448 \\
& & & & & \\
Group 3 & $0.25^{\circ}$ & $0.48 \pm 0.16$ & $0.55 \pm 0.19$ & $0.57 \pm 0.18$ & 0.005 \\
Group 3 & $0.5^{\circ}$ & $0.48 \pm 0.15$ & $0.48 \pm 0.17$ & $0.50 \pm 0.15$ & 0.786 \\
Group 3 & $1^{\circ}$ & $0.32 \pm 0.12$ & $0.31 \pm 0.13$ & $0.34 \pm 0.12$ & 0.596 \\
Group 3 & $1.75^{\circ}$ & $0.11 \pm 0.09$ & $0.12 \pm 0.07$ & $0.13 \pm 0.08$ & 0.743 \\
Group 3 & $3^{\circ}$ & $0.12 \pm 0.08$ & $0.15 \pm 0.07$ & $0.15 \pm 0.07$ & 0.522
\end{tabular}

Values represent mean \pm standard deviation; $n=31$; MPOD $=$ macular pigment optical density; $0.25^{\circ}=\mathrm{MPOD}$ measured at $0.25^{\circ}$ retinal eccentricity; $0.5^{\circ}=\mathrm{MPOD}$ measured at $0.5^{\circ}$ retinal eccentricity; $1^{\circ}=$ MPOD measured at $1^{\circ}$ retinal eccentricity; $1.75^{\circ}=$ MPOD measured at $1.75^{\circ}$ retinal eccentricity; $3^{\circ}=$ MPOD measured at $3^{\circ}$ retinal eccentricity; Group $1(n=10)$ : high $\mathrm{L}$ group $(\mathrm{L}=20 \mathrm{mg} /$ day, $\mathrm{Z}=2 \mathrm{mg} /$ day); Group 2: combined carotenoid group $(\mathrm{MZ}=10 \mathrm{mg} / \mathrm{day}$, $\mathrm{L}=10 \mathrm{mg} /$ day, $\mathrm{Z}=2 \mathrm{mg} /$ day); Group 3 : high $\mathrm{MZ}$ group $(\mathrm{MZ}=17 \mathrm{mg} /$ day, $\mathrm{L}=3 \mathrm{mg} / \mathrm{day}, \mathrm{Z}=2 \mathrm{mg} /$ day); The $p$-values represent repeated measures ANOVA for the 3 study visits (within-subject effects), with Greenhouse-Gesser correction for lack of sphericity as appropriate. to group \& visit.

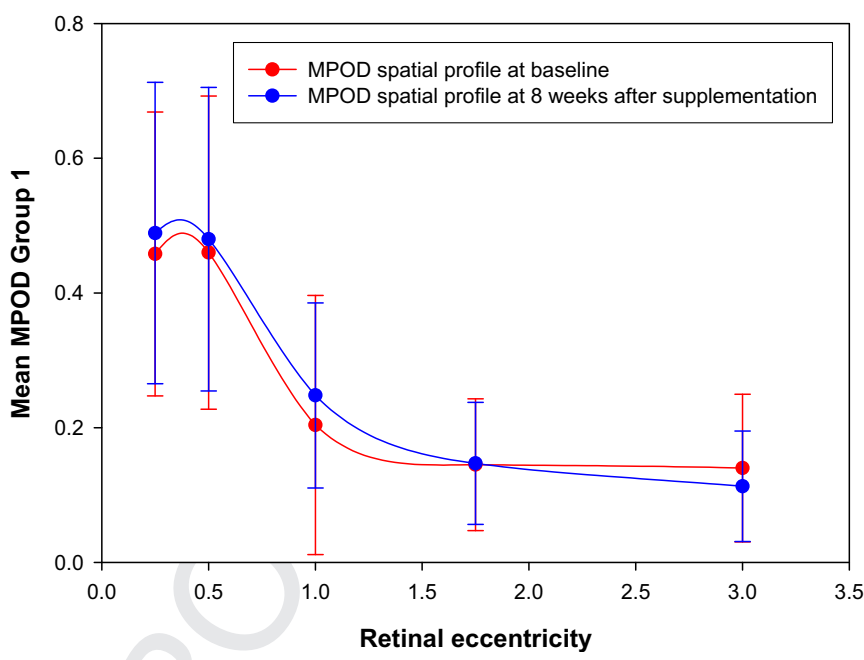

Fig. 2. Mean macular pigment optical density spatial profile of Group 1 at baseline (pre supplementation) and at 8 weeks (post supplementation). Mean \pm standard deviation; $n=10$; Group 1: high $L$ group $(L=20 \mathrm{mg} /$ day, $Z=2 \mathrm{mg} /$ day $)$. The smooth line drawn through the data was achieved using our graphic software Sigma Plot 8.

carotenoid formulations, on the spatial profile of MP in subjects with an atypical MP profile characterized by the lack of the typical central peak. Over an eight week study period, subjects with such a pre-identified and confirmed atypical spatial profile of their MP
Table 3

Individual MPOD values at each degree of retinal eccentricity for all subjects according to group \& visit wise.

\begin{tabular}{|c|c|c|c|c|c|c|c|c|c|c|c|c|c|c|c|c|}
\hline \multirow[t]{2}{*}{ No. } & \multirow[t]{2}{*}{ Group } & \multicolumn{3}{|l|}{$0.25^{\circ}$} & \multicolumn{2}{|l|}{$0.50^{\circ}$} & \multirow{2}{*}{$\overline{8 \mathrm{wks}}$} & \multicolumn{3}{|l|}{$1.0^{\circ}$} & \multicolumn{3}{|l|}{$1.75^{\circ}$} & \multicolumn{3}{|l|}{$3.0^{\circ}$} \\
\hline & & Baseline & $4 \mathrm{wks}$ & 8 wks & Baseline & 4 wks & & Baseline & 4 wks & 8 wks & Baseline & $4 \mathrm{wks}$ & 8 wks & Baseline & 4 wks & $8 \mathrm{wks}$ \\
\hline 1 & Group 1 & 0.86 & 0.88 & 0.95 & 0.88 & 0.74 & 0.88 & 0.02 & 0.43 & 0.2 & 0.24 & 0.21 & 0.17 & 0.2 & 0.13 & 0.02 \\
\hline 4 & Group 1 & 0.47 & 0.52 & 0.53 & 0.43 & 0.5 & 0.51 & 0.11 & 0.24 & 0.19 & 0.07 & 0.14 & 0.13 & 0.09 & 0.16 & 0.06 \\
\hline 7 & Group 1 & 0.14 & 0.16 & 0.3 & 0.13 & 0.18 & 0.3 & 0 & 0 & 0.2 & 0.08 & 0 & 0.1 & 0.16 & 0.2 & 0.22 \\
\hline 8 & Group 1 & 0.31 & 0.33 & 0.28 & 0.28 & 0.3 & 0.34 & 0.12 & 0.14 & 0.23 & 0.12 & 0.07 & 0.17 & 0.06 & 0.18 & 0.15 \\
\hline 11 & Group 1 & 0.7 & 0.72 & 0.7 & 0.76 & 0.72 & 0.75 & 0.67 & 0.55 & 0.57 & 0.37 & 0.3 & 0.32 & 0.38 & 0.26 & 0.26 \\
\hline 12 & Group 1 & 0.29 & 0.31 & 0.3 & 0.3 & 0.32 & 0.28 & 0.2 & 0.33 & 0.2 & 0.06 & 0.1 & 0.06 & 0.03 & 0.11 & 0.09 \\
\hline 19 & Group 1 & 0.53 & 0.6 & 0.6 & 0.61 & 0.66 & 0.66 & 0.29 & 0.37 & 0.37 & 0.1 & 0.23 & 0.23 & 0.25 & 0.07 & 0.07 \\
\hline 2 & Group 2 & 0.55 & 0.61 & 0.75 & 0.57 & 0.57 & 0.57 & 0.73 & 0.31 & 0.44 & 0.29 & 0.3 & 0.27 & 0.34 & 0.16 & 0.39 \\
\hline 3 & Group 2 & 0.28 & 0.39 & 0.45 & 0.29 & 0.25 & 0.38 & 0.32 & 0.17 & 0.3 & 0.18 & 0.19 & 0.17 & 0.24 & 0.07 & 0.05 \\
\hline 9 & Group 2 & 0.23 & 0.28 & 0.34 & 0.27 & 0.31 & 0.27 & 0.36 & 0.17 & 0.31 & 0.23 & 0.14 & 0.24 & 0.34 & 0.1 & 0.21 \\
\hline 10 & Group 2 & 0.04 & 0.27 & 0.28 & 0.12 & 0.24 & 0.25 & 0.02 & 0.21 & 0.25 & 0 & 0.15 & 0.19 & 0 & 0.08 & 0.17 \\
\hline 13 & Group 2 & 0.35 & 0.47 & 0.57 & 0.36 & 0.36 & 0.51 & 0 & 0.17 & 0.33 & 0.01 & 0.13 & 0.21 & 0 & 0.07 & 0.22 \\
\hline 21 & Group 3 & 0.64 & 0.68 & 0.51 & 0.63 & 0.63 & 0.46 & 0.44 & 0.44 & 0.43 & 0.26 & 0.23 & 0.14 & 0.29 & 0.19 & 0.13 \\
\hline 22 & Group 3 & 0.57 & 0.55 & 0.61 & 0.61 & 0.55 & 0.58 & 0.48 & 0.35 & 0.31 & 0.08 & 0.15 & 0.11 & 0.13 & 0.25 & 0.14 \\
\hline 23 & Group 3 & 0.5 & 0.59 & 0.66 & 0.47 & 0.48 & 0.55 & 0.35 & 0.38 & 0.41 & 0.14 & 0.15 & 0.24 & 0.15 & 0.24 & 0.13 \\
\hline 24 & Group 3 & 0.55 & 0.58 & 0.61 & 0.56 & 0.56 & 0.57 & 0.32 & 0.27 & 0.33 & 0.12 & 0.09 & 0.13 & 0.12 & 0.1 & 0.13 \\
\hline 25 & Group 3 & 0.34 & 0.34 & 0.4 & 0.38 & 0.38 & 0.38 & 0.23 & 0.23 & 0.23 & 0 & 0 & 0 & 0.09 & 0.09 & 0.09 \\
\hline 26 & Group 3 & 0.57 & 0.7 & 0.77 & 0.57 & 0.69 & 0.64 & 0.4 & 0.29 & 0.38 & 0.26 & 0.19 & 0.21 & 0.2 & 0.18 & 0.22 \\
\hline 27 & Group 3 & 0.29 & 0.32 & 0.34 & 0.29 & 0.29 & 0.31 & 0.2 & 0.14 & 0.15 & 0.06 & 0.04 & 0.06 & 0.06 & 0.09 & 0.08 \\
\hline 28 & Group 3 & 0.71 & 0.92 & 0.93 & 0.7 & 0.69 & 0.79 & 0.42 & 0.57 & 0.59 & 0.08 & 0.18 & 0.2 & 0.05 & 0.16 & 0.3 \\
\hline 29 & Group 3 & 0.29 & 0.37 & 0.41 & 0.3 & 0.23 & 0.33 & 0.1 & 0.16 & 0.26 & 0 & 0.07 & 0.05 & 0.03 & 0.05 & 0.14 \\
\hline 30 & Group 3 & 0.32 & 0.45 & 0.48 & 0.33 & 0.34 & 0.42 & 0.21 & 0.3 & 0.28 & 0.11 & 0.1 & 0.11 & 0.08 & 0.12 & 0.11 \\
\hline
\end{tabular}

Values represent macular pigment optical density (MPOD) values; $n=31 ; 0.25^{\circ}=$ MPOD measured at $0.25^{\circ}$ retinal eccentricity; $0.5^{\circ}=$ MPOD measured at $0.5^{\circ}$ retinal eccentricity $1^{\circ}=\mathrm{MPOD}$ measured at $1^{\circ}$ retinal eccentricity; $1.75^{\circ}=\mathrm{MPOD}$ measured at $1.75^{\circ}$ retinal eccentricity; $3^{\circ}=$ MPOD measured at $3^{\circ}$ retinal eccentricity; Group $1(n=10)$ : high $\mathrm{L}$ group ( $\mathrm{L}=20 \mathrm{mg} / \mathrm{day}, \mathrm{Z}=2 \mathrm{mg} / \mathrm{day})$; Group $2(n=10)$ : combined carotenoid group ( $\mathrm{MZ}=10 \mathrm{mg} /$ day, $\mathrm{L}=10 \mathrm{mg} /$ day, $\mathrm{Z}=2 \mathrm{mg} /$ day); $\mathrm{Group} 3$ ( $n=10$ ): high $\mathrm{MZ}$ group $\left(\mathrm{MZ}=17 \mathrm{mg} /\right.$ day, $\mathrm{L}=3 \mathrm{mg} / \mathrm{day}, \mathrm{Z}=2 \mathrm{mg} /$ day). Of note, at baseline average MPOD at $0.25^{\circ}$ was significantly less than average MPOD at $0.5^{\circ}$ in the subjects studied here.
467

468

469

470

471

472

473

474

475

476

477

478

479
480

481

482

483

484

485

486

487

488

489

490

491

492
493

494

495

496

497

498

499

500 
(Berendschot and van Norren, 2006; Dietzel et al., 2011; Kirby et al., 2009, 2010; Trieschmann et al., 2003).

Indeed, even in the publication by Hammond et al. in 1997, the authors noted deviations from an exponential function in $40 \%$ of subjects (Hammond et al., 1997). In 2003, Trieschmann et al, reported that the spatial profile of MP, assessed using AF, exhibited four types of distribution, and that MPOD was lower in patients with AMD (Trieschmann et al., 2003). In 2006, Delori et al. described bimodal spatial distributions of MP that were characterized by a central peak of highest MP density surrounded by a ring with high-density values at approximately $0.7^{\circ}$ from the fovea. In the same year, Berendschot and van Norren (2006) confirmed this finding and reported that both reflectance and $A \bar{F}$ maps showed ringlike patterns in the distribution of the MP, and suggested that such patterns follow the distribution of the inner plexiform layer. Indeed, the authors reported a distinct ring pattern in over $50 \%$ of subjects, at a mean distance of $0.7^{\circ}$ from the foveal centre, and noted that in a few subjects, the orbit of the ring has an even greater optical density than did the central peak. Furthermore, Dietzel et al. reported ringlike structures in circa $20 \%$ of subjects, which were less likely to be seen in subjects with AMD. Dietzel et al. also described MP distributions (using AF) as intermediate where there is no strictly monotonic decline from the centre of the fovea to the periphery, but no explicit ringlike pattern of MP, but where an implied plateau exists (Dietzel et al., 2011).

In brief, therefore, there is consensus that inter-individual were supplemented with one of three different carotenoid formuday); Group 2: combined carotenoid group ( $M Z=10 \mathrm{mg} /$ day, $\mathrm{L}=10 \mathrm{mg} /$ day, $\mathrm{Z}=2 \mathrm{mg} /$ day); Group 3: high $\mathrm{MZ}$ group $(\mathrm{MZ}=17 \mathrm{mg} /$ day, $\mathrm{L}=3 \mathrm{mg} /$ day, $\mathrm{Z}=2 \mathrm{mg} /$ day $)$.

Over the last number of years, reports on the spatial profile of MP have generated debate. In 1997, Hammond, Wooten and Snodderly conducted a study in 32 subjects to investigate individual variations in the spatial profile of human MP, and concluded that an exponential decay with eccentricity explained more variance in the distribution than a Gaussian function (Hammond et al., 1997). The MP spatial profile has since been described as a central peak, which decreases with eccentricity to optically undetectable levels by $10^{\circ}$ eccentricity. While it is true that such an exponential decay still describes the MP profile very well (even in subjects with "atypical" profiles), recent study has revealed that there are obvious deviations from a monotonic decline from the central fovea

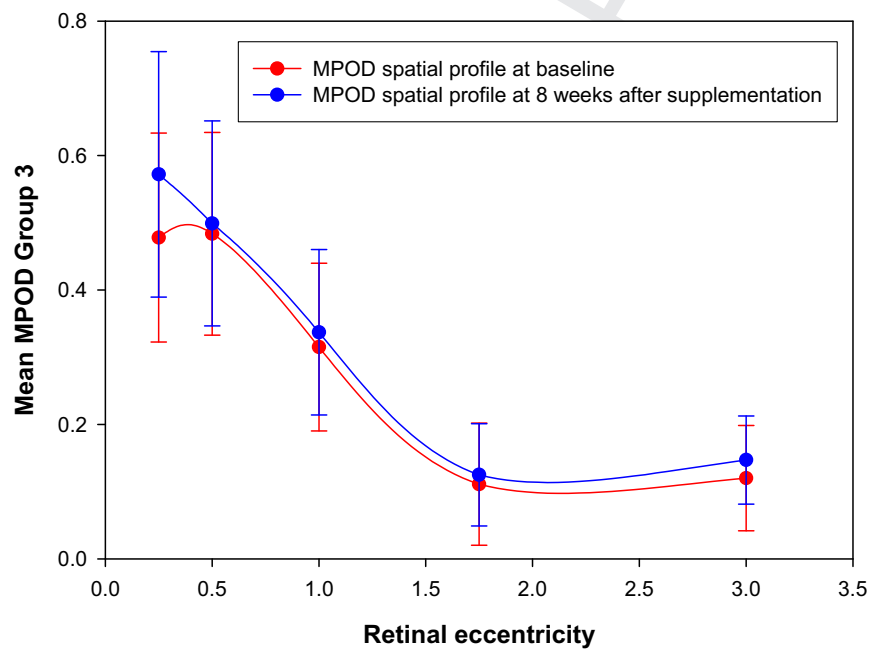

Fig. 4. Mean macular pigment optical density spatial profile of Group 3 at baseline (pre supplementation) and at 8 weeks (post supplementation). Mean \pm standard deviation; $n=10$; Group 3: high $\mathrm{MZ}$ group ( $\mathrm{MZ}=17 \mathrm{mg} /$ day, $\mathrm{L}=3 \mathrm{mg} /$ day, $\mathrm{Z}=2 \mathrm{mg} /$ day). The smooth line drawn through the data was achieved using our graphic software Sigma Plot 8 .

variability, in terms of the spatial distribution of MP, does exist. However, the terminology used to classify such variations has differed, and the terms employed reflect the methodology used to measure MP.

With HFP, for example, a 2-dimensional profile (silhouette) of MP is generated, prompting terms such as "central dip" (Kirby et al., 2010), "minor flanking peaks" (Hammond et al., 1997) or "shoulder" to describe profiles that do not exhibit the typical monotonic decline with eccentricity and that are seen in about $40 \%$ of subjects (Hammond et al., 1997).

Using AF, where an "en face" map is generated, the term "ringlike structure" has been used to describe “...the bimodal pattern of MPOD [is] visible as a ringlike structure with a central peak of MPOD surrounded by a ring of increased density" (Dietzel et al., 2011). We believe the ringlike structures and intermediate profiles described with AF represent the non-monotonic decays of MP that we and others have observed using HFP, given the radial symmetry of MPOD (Hammond et al., 1997). In support of this view is the observation that the former are seen in approximately $50 \%$ of cases using AF (Berendschot and van Norren, 2006) and the latter are seen in approximately $40 \%$ of cases assessed by $\mathrm{HFP}_{4}$ (Hammond et al., 1997). For this reason, and for the purpose of this study, we have defined an atypical profile as one where MPOD at $0.25^{\circ}$ does not exceed MPOD at $0.5^{\circ}$ by more than 0.04 ODU, therefore representing a subgroup of AF-generated ringlike structures or intermediate patterns described by Berendschot and van Norren in a "few" of their subjects (Berendschot and van Norren, 2006).

We report a statistically significant increase in MPOD at $0.25^{\circ}$ retinal eccentricity in the combined carotenoid group (Group 2) and the high MZ group (Group 3), but no increase in MPOD at $0.25^{\circ}$ in the high L group (Group 1 ). With respect to individual responses and magnitude of responses with in the Groups, it is important to note that the increase in MPOD, whether expressed in terms of the proportion of subjects exhibiting a $>10 \%$ rise or in terms of average increase in MPOD, at either 0.25 or 0.5 eccentricity, was substantially greater for subjects in Group 2 (i.e. those supplemented with all three macular carotenoids). Further, Group 2 was unique in that all subjects in this Group exhibited an increase of at least $10 \%$ (i.e. a clinically meaningful response) at $0.25_{\Lambda}^{\circ}$ eccentricity, and was 
also unique in that the average MPOD increase was greater than $100 \%$ at this eccentricity (and this compares with only $13 \%$ and $22 \%$ in Groups 1 and 3, respectively). MP response at this central retinal location is of interest to the current investigation and report, given that the pre-specified hypothesis was that supplementation with appropriate macular carotenoids could realise the typical central peak of MP in subjects selected on the basis that they lacked such (desirable) typical profile at baseline (Kirby et al., 2010). The research question, therefore, was to determine if subjects not exhibiting the typical central peak of MP (at baseline) would respond differently to different macular carotenoid formulations. We hypothesized that supplementation with MZ (as in Groups 2 and 3) may augment central MP in subjects presenting with our predefined and non-peaked MP spatial profiles. The rationale, which informed this hypothesis, was premised on the observation that MZ, which comprises one-third of the human MP, is the most centrally located of the macular carotenoids (Bone et al., 1997) (i.e. the location of the typical central peak of MP (Kirby et al., 2010)).

Of importance to this discussion, macular $\mathrm{MZ}$ is produced primarily by isomerization of macular L, (Neuringer et al., 2004) thus accounting for lower relative levels of $\mathrm{L}$, and higher relative levels of MZ, in the central macula, and vice versa in the peripheral macula (Bone et al., 1988). It is possible, therefore, that the mechanism which converts L to MZ at the macula (which may be enzymatic (Bone et al., 1997) and/or light dependent (Nolan et al., 2009)) is defective in individuals with no observable typical central peak of MP. Indeed, the data presented here is consistent with this hypothesis. Importantly, however, we now confirm that subjects without a typical central peak in their MP spatial profiles do respond to a supplement containing MZ (as seen in Groups 2 and 3 ), but do not respond to a supplement containing high amounts of $\mathrm{L}$ (as seen in Group 1).

The above finding is all the more important, given a recent publication by our group which showed that individuals at increased risk of developing AMD (e.g. cigarette smokers and older people) were more likely to lack the typical central peak in their MP spatial profile (see publication by Kirby et al. (2010)). Possible explanations for this observed association between the atypical non central-peaked MP spatial profile and increased risk of AMD may be attributable to this pigment's physical and chemical properties. For example, the absence of a central peak of MP suggests a lack of MZ, and therefore lower antioxidant activity (Foote et al., 1970; Li et al., 2010) and less short-wavelength light filtering capacity, when compared to individuals with the typical peak of MP at the macular epicentre. Indeed, it is these two properties of MP which have been hypothesized to confer protection against AMD, and therefore merit discussion (see below).

Moreover, our data is consistent with previous publications in AMD populations. For example, a study performed by Trieschmann et al., of 400 subjects ( 253 with signs of early AMD, 147 without AMD), reported that eyes afflicted with AMD were more likely to display low central MPOD when compared to non-AMD subjects (Trieschmann et al., 2003).

Also, we report that enrichment of MP across the full spatial profile (i.e. at $0.25^{\circ}, 0.5^{\circ}, 1^{\circ}, 1.75^{\circ}, 3^{\circ}$ ) was achieved only when subjects were supplemented with all three macular carotenoids (as per Group 2), suggesting a beneficial and may be even an interactively additive effect of supplementing with all three carotenoids. Groups 1 and 3 demonstrated little or no response at the eccentricities beyond $0.25^{\circ}$ (i.e. at $0.5^{\circ}, 1^{\circ}, 1.75^{\circ}, 3^{\circ}$ ). Of interest, the preselected eyes with atypical MP profiles were identified in subjects with high, low and medium levels of baseline MP, thus suggesting that a lack of $L$ is not the cause of a parallel lack of the typical central peak in these subjects, and is consistent with our findings that supplementation with $\mathrm{L}$ alone did not increase
MP significantly, whereas supplementation with L, Z and MZ increased MP significantly (centrally, in the mid periphery and in the periphery of the macula); whereas supplementation with $\mathrm{MZ}$ alone increased MP significantly (but only at the epicenter).

It is important to point out that an 8-week trial of supplemental $\mathrm{L}$ represents a relatively short time period for such a purpose. Indeed, other L-supplementation studies have also failed to significantly augment MP over this time period (Nolan et al., 2011; Trieschmann et al., 2007). However, the subjects tested here were atypical by virtue of the fact that they exhibited central dips or plateaus in their MP spatial profiles, and we sought to specifically investigate whether such subjects would respond differently to different carotenoid interventions. Interestingly, only those carotenoid formulations in the current study that contained MZ achieved a rapid response in central MPOD over this time period.

The above findings, however, are consistent with a publication by Connolly et al. who found that enrichment of MP centrally, and across its spatial profile, is achieved in subjects (both normal and AMD-afflicted) supplemented with all three macular carotenoids (Connolly et al., 2010). This notion is also consistent with in vitro studies reporting better functionality of the macular carotenoids when in combination rather than in isolation (Li et al., 2010). Possible functional implications of enrichment of MP centrally in subjects lacking the typical central peak of MP (i.e. following supplementation with MZ; Group 2 and Group 3), and across its full spatial profile (Group 3 only) are discussed below. Also, the increase in central MPOD, seen in Groups 2 and 3, is likely to confer optical benefits at this location (i.e. enhanced contrast sensitivity and ameliorated glare disability) (Nolan et al., 2011).

In addition, an increase in central MP will facilitate antioxidant activity at this retinal locus, whether the subject suffers from AMD or is at risk of developing this condition. From an antioxidant perspective, $\mathrm{L}, \mathrm{Z}$ and $\mathrm{MZ}$ are structural isomers of one another and are characterized, biochemically, by their high number of doublebonds (Bone et al., 1993). Their supply of readily available electrons enables these carotenoids to quench reactive oxidative intermediates (ROIs), thus limiting membrane phosopholipid peroxidation

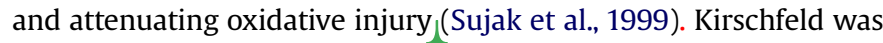
the first to propose the idea that carotenoids protect the macula against oxidative stress, (Kirschfeld, 1982) and in 1997, Khachik et al. confirmed the presence of direct oxidation products of $\mathrm{L}$ and $\mathrm{Z}$ in human retinal tissue, supporting the hypothesis that MP does indeed protect against oxidative damage in this tissue (Khachik et al., 1997).

Of note, MP is at its highest concentration in the receptor axon layer of the foveola and in the inner and outer plexiform layers of the macula (Snodderly et al., 1984a; Trieschmann et al., 2008). Also, the concentration of the carotenoids with in each retinal layer peaks at the foveola (where the ratio of $\mathrm{MZ}$ to $\mathrm{L}$ and $\mathrm{Z}$ is maximum). Importantly, it is at this central retinal location where ROI production is greatest. In vitro studies of human RPE cells, subjected to oxidative stress, have demonstrated enhanced survival of these cells in the presence of $\mathrm{Z}$ and other antioxidants, when compared with controls (Wrona et al, 2004). $Z$ appears to be a more potent antioxidant than L (Cantrell et al., 2003) and MZ is yet more efficacious, but only in conjunction with its binding protein (Bhosale and Bernstein, 2005). Recently, Li et al. demonstrated that a mixture of $\mathrm{L}, \mathrm{Z}$ and $\mathrm{MZ}$ (in a ratio of $1: 1: 1$ ) quenches more singlet oxygen than any of these carotenoids individually but at the same total concentration ${ }_{\mathcal{C}}(\mathrm{Li}$ et al., 2010). This collective optimization of antioxidant activity, dependent on the presence of all three macular carotenoids, could prevent depletion of MP in such a high oxidative stress environment. In other words, MP with inadequate quantities of any of the three macular carotenoids may lack sufficient antioxidant potential to stabilize the pigment in a high oxidative stress environment, such as the central retina. 
From a light filtering perspective, $\mathrm{L}$ is reported to be a superior filter of blue light when compared to $\mathrm{Z}$, due to its orientation with respect to the plane of the phospholipid bilayer of the cell membrane, (Sujak et al, 1999) which is both parallel and perpendicular. In contrast, $\mathrm{Z}$ and MZ only exhibit perpendicular orientation to this layer. However, it is important to note that the different absorption spectra of these pigments (L, Z and $\mathrm{MZ}$ ) result in a collective optimal filtration of blue light at the macula, which would not be achieved by any of these carotenoids in isolation.

In conclusion, we report that the typical central peak of MP can be realised in subjects who do not exhibit such typical and peaked spatial profiles of this pigment, when supplemented with a preparation containing $\mathrm{MZ}$, by not when supplemented with a formulation lacking this carotenoid. In addition, we found that enrichment of MP across its spatial profile can be best achieved following supplementation with all three macular carotenoids (MZ, Z and L). The implications of our findings, in terms of visual performance and/or a (photo)-protective effect, warrant study.

\section{Disclosure}

Mukunda C Akkali-None.

Dr. James Loughman does consultancy work for nutraceutical companies in a personal capacity. Dr. John M. Nolan and Professor Stephen Beatty do consultancy work for nutraceutical companies, in a personal capacity, and as directors of Nutrasight Consultancy Limited. Dr. Alan Howard is a Chairman of the Howard Foundation, a foundation that supports research in the field of nutrition and health.

\section{Acknowledgements}

This study was supported by a grant from The Howard Foundation, Cambridge, CB22 5LA, United Kingdom.

\section{References}

Bartlett, H.E., Eperjesi, F., 2008. A randomised controlled trial investigating the effect of lutein and antioxidant dietary supplementation on visual function in healthy eyes. Clin. Nutr. 27, 218-227.

Berendschot, T.T.J.M., van Norren, D., 2006. Macular pigment shows ringlike structures. Invest. Ophthalmol. Vis. Sci. 47, 709-714.

Bhosale, P., Bernstein, P.S., 2005. Synergistic effects of zeaxanthin and its binding protein in the prevention of lipid membrane oxidation. Biochim. Biophys. Acta $1740,116-121$.

Bone, R.A., Landrum, J.T., Fernandez, L., Tarsis, S.L., 1988. Analysis of the macular pigment by HPLC - retinal distribution and age study. Invest. Ophthalmol. Vis. Sci. 29, 843-849.

Bone, R.A., Landrum, J.T., Hime, G.W., Cains, A., Zamor, J., 1993. Stereochemistry of the human macular carotenoids. Invest. Ophthalmol. Vis. Sci. 34, 2033-2040.

Bone, R.A., Landrum, J.T., Friedes, L.M., Gomez, C.M., Kilburn, M.D., Menendez, E. Vidal, I., Wang, W.L., 1997. Distribution of lutein and zeaxanthin stereoisomers in the human retina. Exp. Eye Res. 64, 211-218.

Cantrell, A., McGarvey, D.J., Truscott, T.G., Rancan, F., Bohm, F., 2003. Singlet oxygen quenching by dietary carotenoids in a model membrane environment. Arch. Biochem. Biophys. 412, 47-54.

Connolly, E.E., Beatty, S., Thurnham, D.I., Loughman, J., Howard, A.N., Stack, J., Nolan, J.M., 2010. Augmentation of macular pigment following supplementation with all three macular carotenoids: an exploratory study. Curr. Eye Res. 35 335-351.

Delori, F.C., Goger, D.G., Keilhauer, C., Salvetti, P., Staurenghi, G., 2006. Bimodal spatial distribution of macular pigment: evidence of a gender relationship. J. Opt. Soc. Am. A Opt. Image Sci. Vis 23, 521-538.

Dietzel, M., Zeimer, M., Heimes, B., Pauleikhoff, D., Hense, H.W., 2011. The ringlike structure of macular pigment in age-related maculopathy: results from the Muenster Aging and Retina Study (MARS). Invest. Ophthalmol. Vis. Sci. 52, 8016-8024.

Engles, M., Wooten, B., Hammond, B., 2007. Macular pigment: a test of the acuity hypothesis. Invest. Ophthalmol. Vis. Sci. 48, 2922-2931.

Foote, C.S., Chang, Y.C., Denny, R.W., 1970. Chemistry of singlet oxygen. X. Carotenoid quenching parallels biological protection. J. Am. Chem. Soc. 92, 5216-5218.
Hammond, B.R., Wooten, B.R., Snodderly, D.M., 1997. Individual variations in the spatial profile of human macular pigment. J. Opt. Soc. America A-Optics Image Sci. Vis. 14, 1187-1196.

Hammond Jr., B.R., Wooten, B.R., 2005. CFF thresholds: relation to macular pigment optical density. Ophthalmic Physiol. Opt. 25, 315-319.

Hirsch, J., Curcio, C.A., 1989. The spatial resolution capacity of human foveal retina. Vis. Res. 29, 1095-1101.

Johnson, E.J., Neuringer, M., Russell, R.M., Schalch, W., Snodderly, D.M., 2005. Nutritional manipulation of primate retinas, III: effects of lutein or zeaxanthin supplementation on adipose tissue and retina of xanthophyll-free monkeys. Invest. Ophthalmol. Vis. Sci. 46, 692-702.

Khachik, F., Bernstein, P.S., Garland, D.L., 1997. Identification of lutein and zeaxanthin oxidation products in human and monkey retinas. Invest. Ophthalmol. Vis. Sci. 38, 1802-1811.

Kirby, M.L., Galea, M., Loane, E., Stack, J., Beatty, S., Nolan, J.M., 2009. Foveal anatomic associations with the secondary peak and the slope of the macular pigment spatial profile. Invest. Ophthalmol. Vis. Sci. 50, 1383-1391.

Kirby, M.L., Beatty, S., Loane, E., Akkali, M.C., Connolly, E.E., Stack, J., Nolan, J.M., 2010. A central dip in the macular pigment spatial profile is associated with age and smoking. Invest. Ophthalmol. Vis. Sci. 51, 6722-6728.

Kirschfeld, K., 1982. Carotenoid pigments: their possible role in protecting against photooxidation in eyes and photoreceptor cells. Proc. R. Soc. Lond B Biol. Sci. 216, 71-85.

Klaver, C.C.W., Wolfs, R.C.W., Vingerling, J.R., Hofman, A., De Jong, P.T.V.M., 1998. Age-specific prevalence and causes of blindness and visual impairment in an older population - The Rotterdam Study. Arch. Ophthalmol. 116, 653-658.

Kvansakul, J., Rodriguez-Carmona, M., Edgar, D.F., Barker, F.M., Kopcke, W., Schalch, W., Barbur, J.L., 2006. Supplementation with the carotenoids lutein or zeaxanthin improves human visual performance. Ophthalmic Physiol. Opt. 26, 362-371.

Li, B., Ahmed, F., Bernstein, P.S., 2010. Studies on the singlet oxygen scavenging mechanism of human macular pigment. Arch. Biochem. Biophys 504, 56-60.

Loughman, J., Akkali, M.C., Beatty, S., Scanlon, G., Davison, P.A., O’Dwyer, V., Cantwell, T., Major, P., Stack, J., Nolan, J.M., 2010. The relationship between macular pigment and visual performance. Vis. Res. 50, 1249-1256.

Neuringer, M., Sandstrom, M.M., Johnson, E.J., Snodderly, D.M., 2004. Nutritional manipulation of primate retinas, I: effects of lutein or zeaxanthin supplements on serum and macular pigment in xanthophyll-free rhesus monkeys. Invest. Ophthalmol. Vis. Sci. 45, 3234-3243.

Nolan, J.M., O'Reilly, P., Loughman, J., Stack, J., Loane, E., Connolly, E., Beatty, S., 2009. Augmentation of macular pigment following implantation of blue light-filtering intraocular lenses at the time of cataract surgery. Invest. Ophthalmol. Vis. Sci. 50, 4777-4785.

Nolan, J.M., Loughman, J., Akkali, M.C., Stack, J., Scanlon, G., Davison, P., Beatty, S. 2011. The impact of macular pigment augmentation on visual performance in normal subjects: COMPASS. Vis. Res. 51, 459-469.

Rodriguez-Carmona, M., Kvansakul, J., Harlow, J.A., Kopcke, W., Schalch, W. Barbur, J.L., 2006. The effects of supplementation with lutein and/or zeaxanthin on human macular pigment density and colour vision. Ophthalmic Physiol. Opt. 26, 137-147.

Snodderly, D.M., Auran, J.D., Delori, F.C., 1984a. The macular pigment. II. Spatial distribution in primate retinas. Invest. Ophthalmol. Vis. Sci. 25, 674-685

Snodderly, D.M., Brown, P.K., Delori, F.C., Auran, J.D., 1984b. The macular pigment .1. Absorbance spectra, localization, and discrimination from other yellow pigments in primate retinas. Invest. Ophthalmol. Vis. Sci. 25, 660-673.

Snodderly, D.M., Handelman, G.J., Adler, A.J., 1991. Distribution of individual macular pigment carotenoids in central retina of macaque and squirrel monkeys. Invest. Ophthalmol. Vis. Sci. 32, 268-279.

Stringham, J.M., Hammond Jr., B.R., 2007. The glare hypothesis of macular pigment function. Optom. Vis. Sci. 84, 859-864.

Stringham, J.M., Hammond, B.R., 2008. Macular pigment and visual performance under glare conditions. Optom. Vis. Sci. 85, 82-88.

Stringham, J.M., Fuld, K., Wenzel, A.J., 2004. Spatial properties of photophobia. Invest. Ophthalmol. Vis. Sci. 45, 3838-3848.

Sujak, A., Gabrielska, J., Grudzinski, W., Borc, R., Mazurek, P., Gruszecki, W.I., 1999. Lutein and zeaxanthin as protectors of lipid membranes against oxidative damage: the structural aspects. Arch. Biochem. Biophys. 371, 301-307.

Trieschmann, M., Spital, G., Lommatzsch, A., van Kuijk, F.J.G.M., Fitzke, F., Bird, A., Pauleikhoff, D., 2003. Macular pigment: quantitative analysis on autofluorescence images. Graefes Arch. Clin. Exp. Ophthalmol. 241, 1006-1012.

Trieschmann, M., Beatty, S., Nolan, J.M., Hense, H.W., Heimes, B., Austermann, U., Fobker, M., Pauleikhoff, D., 2007. Changes in macular pigment optical density and serum concentrations of its constituent carotenoids following supplemental lutein and zeaxanthin: the LUNA study. Exp. Eye Res. 84, 718-728.

Trieschmann, M., van Kuijk, F.J., Alexander, R., Hermans, P., Luthert, P., Bird, A.C., Pauleikhoff, D., 2008. Macular pigment in the human retina: histological evaluation of localization and distribution. Eye 22, 132-137.

Wooten, B.R., Hammond, B.R., 2002. Macular pigment: influences on visual acuity and visibility. Prog. Retin. Eye Res. 21, 225-240.

Wooten, B.R., Hammond, B.R., 2005. Spectral absorbance and spatial distribution of macular pigment using heterochromatic flicker photometry. Optom. Vis. Sci. 82, 378-386.

Wrona, M., Rozanowska, M., Sarna, T., 2004. Zeaxanthin in combination with ascorbic acid or alpha-tocopherol protects ARPE-19 cells against photosensitized peroxidation of lipids. Free Radic. Biol. Med 36, 1094-1101. 